\title{
O CONCEITO FREUdiano de PUlsão (TRIEb) E ALgumas DE SUAS IMPLICAÇÕES EPISTEMOLÓGICAS ${ }^{\star}$
}

Helio Honda ${ }^{\star}$

\begin{abstract}
Resumo
$O$ artigo analisa o conceito de pulsão [Trieb] e discute algumas das implicações epistemológicas dele decorrentes para o estatuto da psicanálise. Tais implicações estariam diretamente relacionadas 1) com a demarcação de um campo de estudo, o terreno propriamente psicanalítico, 2) com a natureza dos fenomenos que habitam o terreno assim demarcado e que, portanto, tem a ver 3) com o estatuto epistemológico da psicanálise como disciplina científica autônoma. Detém-se na análise do significado da pulsão como representante psíquico dos estímulos provenientes do interior do corpo, a fim de evidenciar o caráter erógeno da realidade psíquica.

Palavras-chave: pulsão; trieb; realidade psíquica; metapsicologia.

\section{The FREUdian CONCEPT OF INSTINCT (TRIEB) AND SOME OF ITS EPISTEMOLOGICAL IMPLICATIONS}

\begin{abstract}
The article analyzes the concept of instinct [Trieb] and discusses some of the epistemological implications to the status of psychoanalysis. Such implications would be directly related to 1) the demarcation of a field of study, the psychoanalytic field itself, 2) the nature of the phenomena that inhabit the land so marked, and which therefore has to do 3) with the epistemological status of psychoanalysis as a scientific and autonomous discipline, including independent of other psychologies. The analysis is focused on the meaning of the instinct as a psychical representative of the stimuli that comes from inside the body, in order to highlight the main erogenous nature of psychic reality.
\end{abstract}

Keywords: instinct; trieb; psychical reality; metapsychology.

\footnotetext{
^ Trabalho vinculado ao Projeto de Pesquisa financiado pelo CNPq Proc. Nr. 401857/2008-5.

* Professor do Departamento de Psicologia e do Programa de Pós-Graduação em Psicologia da Universidade Estadual de Maringá. Endereço: Av. Colombo, 5790. Bloco 118. CEP: 87020-900 - Maringá, PR.

E-mail: hhonda@uem.br
} 
Sugiro que a história típica de um conceito, seja ele 'elemento químico', 'átomo', 'o inconsciente' ou qualquer outro, envolve uma aparição inicial do conceito como uma idéia vaga, seguido por seu esclarecimento gradual quando a teoria na qual ele desempenha um papel assume uma forma mais precisa e coerente (CHALMERS, 1993, p. 112).

\section{INTRODUÇão}

Este trabalho analisa algumas das implicações para o estatuto da psicanálise freudiana decorrentes do conceito de pulsão, apresentado por Freud (1967b) em 1915, em "Pulsões e Destinos da Pulsão". A discussão é, porém, focalizada unicamente sobre a construção do conceito e, portanto, não abrange as questões que ocupam a maior parte do texto, como os diferentes destinos seguidos pela pulsão. ${ }^{1}$ Por implicar em análises que ultrapassam o escopo deste artigo, também não abordamos o segundo dualismo pulsional. Propomo-nos a explorar alguns dos parágrafos iniciais do texto de Freud, detendo-nos na análise do parágrafo em que Freud introduz a definição do conceito de pulsão como representante psíquico dos estímulos que provém do interior do corpo. O objetivo é discutir algumas das implicações de caráter epistemológico que podem ser derivadas da análise do conceito de pulsão, implicações que, pretendemos demonstrar, estão relacionadas de forma direta (a) com a demarcação de um campo de estudo, o terreno propriamente psicanalítico, (b) com a natureza dos fenômenos que habitam o terreno assim demarcado e que, portanto, tem a ver (c) com o estatuto epistemológico da psicanálise como disciplina científica autônoma.

O trabalho está estruturado em dois eixos principais. No primeiro, detemo-nos na análise do conceito de pulsão, para, no segundo eixo, discutir algumas de suas implicações epistemológicas para a metapsicologia, a partir da recuperação dos pressupostos estabelecidos por Freud na construção do conceito de pulsão. No centro da discussão encontra-se o esforço em estabelecer as linhas conceituais fundamentais para a consideração da natureza erógena do psiquismo tematizado por Freud.

\section{AnÁlise (deCOMPOSIÇÃo) do CONCEITO de PUlSÃo}

Costuma-se referir ao conceito de pulsão (Trieb) como aquele que designa o limite entre o somático e o psíquico, um conceito-limite ou conceito fronteiriço que, por alguns aspectos, assemelhar-se-ia à noção de instinto (Instinkt), mas, que, por outros, distinguir-se-ia radicalmente deste. A semelhança estaria na idéia de tendência ou ímpeto a agir, isto é, genericamente falando, ambos os termos se prestariam a expressar uma necessidade que compele o organismo em direção a alguma ação na realidade. Para alguns, porém, a diferença seria radical (LAPLANCHE; PONTALIS, 2001). Ao contrário da rigidez do comportamento que caracterizaria a ação imposta pelo instinto, cujo modelo poderia ser o da ação sexual animal mais rigidamente orientada a objetos sexuais específicos, pois seria desempenhada quase que exclusivamente em vista da reprodução, o comporta- 
mento motivado pulsionalmente pode passar por caminhos os mais variados até alcançar sua meta, que, no caso da pulsão sexual, não precisa ser, necessariamente, a reprodução. Considerações etimológicas e análises pormenorizadas do uso desses termos por parte de Freud revelam, porém, que essa diferença não se sustentaria (HANNS, 2004; SOUZA, 2010). De qualquer modo, como conceito composto, toda pulsão tem como fonte o somático, expressa-se psiquicamente como uma pressão ou força constrangedora, e apresenta uma meta específica, a satisfação, alcançada mediante algum objeto. É igualmente por essa razão que se costuma dizer que o objeto da pulsão é um elemento intercambiável, substituível, quer dizer, que, para alcançar sua meta, para obter satisfação, a pulsão pode lançar mão dos mais diferentes objetos.

Mas, que diz Freud? Em quais termos é apresentado o conceito de pulsão no texto em que visa defini-lo ? $^{2}$ Leiamos integralmente a definição apresentada por Freud em 1915, em "Pulsões e Destinos da Pulsão", para depois analisá-las.

Se voltarmo-nos agora para a consideração da vida anímica [Seelenlebens] do ponto de vista biológico, então a "pulsão" ["Trieb"] nos aparecerá [a] como um conceito-limite [Grenzbegriff] entre o anímico e o somático, [b] como a representante psíquica [psychischer Repräsentant] dos estímulos que provêm do interior do corpo e alcançam a alma [Seele], [c] como uma medida da exigência de trabalho imposto ao anímico em conseqüência de sua relação com o corporal (FREUD, 1967b, p. 214, tradução nossa).

Como podemos ler na definição de Freud, conceito-limite ou conceito fronteiriço entre o psíquico e o somático é apenas um dos significados do conceito de pulsão, o significado mais amplo e superficial. Além deste, que apresenta a pulsão como aquilo que marca os contornos do campo psíquico investigado pela psicanálise frente ao somático, temos dois outros significados de nível mais profundo e específico; a pulsão é também definida como (b) a representante (Repräsentant) psíquica dos estímulos nascidos no interior do corpo, assim como (c) uma medida de exigência de trabalho imposto ao psíquico devido sua relação com o corpo. Convém examinar com um pouco de detalhes cada um desses significados.

\subsection{Pulsão como um Conceito-limite entre o psíquico e o somático.}

O conceito de pulsão "como um conceito-limite entre o psíquico e o somático" está a serviço da demarcação da fronteira entre o mental e o corporal, isso parece claro. Mas, o uso de uma notação diferenciada para se referir à pulsão parece significativo, pois, ao invés de usar simplesmente a palavra Begriff, conceito, Freud compõe um vocábulo novo, Grenzbegriff, conceito-limite, conceito do limite ou da fronteira. Nossa compreensão é a de que, além da função demarcadora, a pulsão, como conceito-limite, tem o papel de nomear o terreno demarcado. Isto é, tratar-se-ia, obviamente, da circunscrição do terreno do psíquico, mas não a compreendemos como uma psique qualquer, permeada pelas indefinições peculiares ao termo corrente entre as psicologias e contaminada por 
dificuldades de relação com o corporal, mas a compreendemos como uma psique pulsional por natureza. Em outras palavras, entendemos o conceito de pulsão como, por um lado, de-marcando, de-limitando as fronteiras tradicionalmente consideradas entre o psíquico e o somático, quer dizer, estabelecendo os limites daquilo que pode ser considerado psíquico e, portanto, investigado por métodos psicológicos; por outro, mais importante, anunciando e dando notícias sobre a natureza do psíquico assim demarcado e o tipo de relação que estabelece com o somático. É o que podemos depreender dos termos que Freud vai introduzir na seqüência do texto para falar da pulsão, ou seja, "alguns termos utilizados em conexão com o conceito de pulsão, como: pressão [Drang], meta [Ziel], objeto [Objekt] e fonte [Quelle] da pulsão" (FREUD, 1967b, p. 214). Embora a fonte da pulsão - porque somática - esteja localizada além dos limites passíveis de investigação pelos métodos psicológicos, ela, assim como os demais termos, designa um atributo ou qualidade constitutiva dos fenômenos psíquicos considerados do ponto de vista pulsional. Apesar de ainda pouco claro, esse primeiro significado do conceito de pulsão pode ser melhor esclarecido ao ser complementado pelos dois outros discutidos a seguir.

\subsection{Pulsão COMO REPRESENTANTE PSíQUiCO dOS ESTÍMUlOS CORPORAIS}

O segundo significado veiculado pelo conceito é o da pulsão "como representante psíquico (psychischer Repräsentant) dos estímulos que provém do interior do corpo". Dizer que os eventos psíquicos devem ser qualificados como eventos pulsionais, significa dizer que tais eventos representam outras coisas. Essas outras coisas representadas, diz Freud, são as excitações nascidas de alguma fonte (Quelle) corporal, originadas no interior do corpo.

Precisamos nos deter um pouco também sobre o uso que faz Freud da palavra Repräsentant, representante, no sentido de alguém delegado para representar um grupo, um exemplar típico de uma classe, enfim, uma espécie de procurador (DUDEN, 1999). Se nesta acepção a pulsão é entendida como representante psíquico dos estímulos oriundos do corpo, tudo se passa, então, como se, p. ex., a sede ou a fome corporais tivessem no psiquismo seu "representante", seu procurador, como aquele que traduz e presentifica no plano do anímico aquilo que tem a ver com as demandas somáticas da fome ou da sede, dando concretude no psiquismo a espécies de sede ou fome anímicas. Freud (1967c) dirá que essa presentificação, essa delegação (no sentido do Repräsentant) é efetivada mediante o representante da pulsão (Triebrepräsentanz), o representante psíquico (psychischen Repräsentanz).

A delegação ou apresentação psíquica da pulsão não se dá, porém, por algum elemento singular, mas por um composto, a saber, por uma idéia ou grupo de idéias ([Vorstellung, Vorstellungsgruppe) ocupadas (besetzt) por uma quantidade de energia ou carga afetiva. Isto é, a pulsão é apresentada no psiquismo pelo representante ideativo (Objekt) e pelo representante afetivo, a quantidade de energia, o fator pressionante (Drang) que coage para a atividade psíquica, este último considerado por Freud (1967b) a essência da pulsão. 
A partir das hipóteses levantadas desde as observações clínicas desenvolvidas nos primórdios da psicanálise, Freud dirá que a repressão (Verdrängung) incide exatamente sobre essa composição, entre Drang e Objekt, inerente ao representante psíquico da pulsão (psychischen Repräsentanz des Triebes), cindindo-a, decompondo-a, resultando daí destinos distintos para o componente representante ideativo (Vorstellungsrepräsentanz) e para o componente delegado energético ou afetivo (Affektbetrag). ${ }^{3}$ De acordo com a conceituação freudiana, portanto, a delegada psíquica da pulsão sexual deve ser compreendida como aquilo mediante a qual é presentificada no psiquismo a erogeneidade nascida no corpo (zonas erógenas). Isto é, com o conceito de pulsão sexual compreende-se que, na concepção de Freud, a sexualidade - a erogeneidade corporal - é delegada no psiquismo por idéias ocupadas por energia sexual ou libido, razão pela qual compreender o psiquismo inconsciente como pulsional implica em compreendêlo como essencialmente dinâmico e erógeno em sua plenitude. Passemos, então, ao exame da noção de erogeneidade, compreendida por Freud (1967a) como a propriedade do corpo próprio e seus órgãos em produzir excitações sexuais.

\subsection{Pulsão Como medida da EXIGÊnCIA de trabalho IMPOSTA AO PSÍQUICO}

A pulsão também é entendida como a "medida da exigência de trabalho imposta ao psíquico em conseqüência de sua relação com o corporal" (FREUD, 1967b, p. 214). A análise dos dois significados anteriores já nos deu sinais de que com o conceito de pulsão Freud não visa designar um fenômeno psíquico singular ou estático, mas que o conceito, além de conceito-limite, é um conceito polissêmico, transitivo e dinâmico, mediante o qual Freud visa caracterizar certos aspectos da natureza dos fenômenos psíquicos. Do ponto de vista do dinamismo erógeno inerente ao conceito de pulsão, o corporal encontra-se presentificado, representado (no sentido do Repräsentant) no anímico, não sendo o psíquico concebível sem o corporal, já que por ser a fonte [Quelle] da pulsão a erogeneidade corporal é constitutiva do psíquico.

Mas, o terceiro significado do conceito de pulsão traz-nos informações adicionais que nos ajuda a compreender outra das características dos fenômenos psíquicos pulsionais. A expressão "exigência de trabalho" designa certa intensidade e coação para a atividade psíquica. "Sob a pressão [Drang] de uma pulsão compreende-se o seu fator motor, a soma de força ou a medida de exigência de trabalho [Arbeitsanforderung], que ela representa [repräsentiert]. O caráter pressionante é uma propriedade geral da pulsão, sua essência" (FREUD, 1967b, p. 214). Em outras palavras, por um lado, temos um aspecto quantitativo ou econômico presentificado em todo evento psíquico entendido como pulsional, a expressão psíquica da erogeneidade corporal, das excitações sexuais que, nascidas de fontes (Quelle) corporais, alcançam a psique e clamam por satisfação; e, por outro lado, temos que, devido ao princípio que o regula, é justamente a elevação no nível excitatório no sistema psíquico que o impele a livrar-se de todo aumento de tensão, pondo-o em atividade. Assim, a expressão "medida da exigência de trabalho imposto ao psíquico" (FREUD, 1967b, p. 214) pode ser entendida como 
a expressão do nível quantitativo, da intensidade de uma demanda erógena que ativa e põe em movimento o psiquismo, porque desde o Projeto de uma psicologia, de 1895, a pulsão já era compreendida como a "mola-mestra [Triebfeder] do mecanismo psíquico" (FREUD, 1987, p. 408, grifo do autor).

Os aspectos econômico e dinâmico da exigência de trabalho contida nessa terceira acepção do conceito de pulsão, bem como as duas acepções antes discutidas, só se tornam mais claras quando levamos em consideração o contexto no qual se insere a discussão da pulsão, a saber, certos pressupostos e conceitos adjacentes com os quais Freud inicia e circunscreve a discussão do tema. Passemos, então, na seqüência do trabalho à análise desses pressupostos, os quais podem ajudar-nos a compreender melhor a natureza da própria pulsão e o alcance desse conceito.

\section{IMPLICAÇÕES EPISTEMOLÓGICAS DERIVADAS dO CONCEITO DE PULSÃO:}

\section{A NATUREZA ERÓGENA DA REALIDADE PSÍQUICA}

Tomadas em conjunto, os três significados do conceito de pulsão acima analisados proporcionam esclarecimentos razoáveis, contudo, ao relermos as palavras de Freud contidas na citação tomada como ponto de partida para nossa análise, percebemos um detalhe importante, qual seja, o de que Freud não utiliza uma linguagem afirmativa para expressar o conceito de pulsão. Ele lança mão de um enunciado condicional: "Se' voltarmo-nos agora para a consideração da vida anímica do ponto de vista biológico, 'então' a 'pulsão' nos aparecerá [...]" (FREUD, 1967b, p. 214, grifo nosso, tradução nossa). Um enunciado desse tipo, como se sabe, é utilizado quando queremos estabelecer uma relação de subordinação de um conteúdo em relação a outro. Isso quer dizer que, no caso, os três significados apresentados pelo conceito de pulsão estariam vinculados de forma lógica a um ponto de vista específico sobre a vida psíquica, a saber, o ponto de vista biológico. Mas, a que perspectiva biológica Freud estaria se referindo? Seria o conceito de pulsão um conceito biológico? E, se pulsão for um conceito tributário de uma perspectiva biológica, qual o sentido dessa dívida, ou seja, até onde e o quê teria a pulsão de biológico? Para tentar esclarecer questões como essas, é necessário conhecer como Freud entende um conceito teórico, seu papel na atividade de produção de conhecimento e o processo pelo qual um conceito ganha uma definição e seu conteúdo semântico.

Retomemos, então, as linhas iniciais do texto de 1915, pois, por este caminho teremos a chance de conhecer um pouco das opiniões de Freud sobre a natureza e gênese de um conceito teórico, em geral, e do conceito de pulsão, em particular. Na seqüência, informações sobre as idéias de Freud acerca da gênese de um conceito servir-nos-ão de guia para conhecer melhor o modo como Freud engendra o conceito de pulsão a partir de perspectivas situadas em outros ramos do conhecimento, como na biologia e na fisiologia. 


\subsection{FunÇão EPISTEMOLÓGICA E CONSTRUÇÃo DE UM CONCEITO TEÓRICO}

A posição de Freud é a de que nenhuma ciência começa a ser construída pela definição de seus conceitos fundamentais, tampouco concorda com uma posição indutivista ingênua que considera a observação isenta de hipóteses como o ponto de partida e fundamento do conhecimento científico (CHALMERS, 1993). Como o indutivista, porém, para ele em seus começos toda atividade científica detém-se em descrições dos fenômenos para depois agrupá-los e relacioná-los entre si. Mas, longe de uma posição indutivista ingênua, essa etapa descritiva e classificatória não deve ser concebida como se fosse possível a partir de uma observação pura, isenta de hipóteses e idéias iniciais diretivas. Ao contrário, já neste primeiro contato com os fenômenos, não é possível evitar a aplicação de certas idéias abstratas. É o que escreve Freud: "É inevitável que, já na descrição, apliquemos sobre o material certas idéias abstratas obtidas não só a partir das novas experiências, mas também oriundas de outras fontes" (FREUD, 1967b, p. 210, tradução nossa). Mais: serão justamente essas idéias iniciais diretoras que, melhor elaboradas no confronto regular com a realidade empírica, possibilitarão a ordenação e circunscrição dos conteúdos que darão corpo aos conceitos fundamentais de uma ciência, a partir daí, necessários para guiar a prática posterior. Em suas palavras: "Ainda mais imprescindíveis são tais idéias [abstratas] - os futuros conceitos fundamentais da ciência - na elaboração [Verarbeitung] posterior do material" (FREUD, 1967b, p. 210, tradução nossa).

No começo, essas idéias encontram-se indefinidas e obscuras, sendo difícil circunscrever seu conteúdo, por isso, ressalva Freud, até que essas idéias sejam tornadas mais claras e precisas, é necessário confrontá-las repetidas vezes com o material empírico, material este que, ao contrário do que pensa o indutivista, apenas aparentemente seria a fonte daquelas idéias. Na verdade, é o inverso, ressalva igualmente Freud. São as idéias iniciais que tornam possível a observação do material, quer dizer, são elas que nos possibilitam "enxergar" o que observamos da maneira como o percebemos. Aqui é importante ler as palavras do próprio Freud. Escreve ele: "Enquanto elas [as idéias] se encontrarem nesse estado [de indefinição], concorda-se sobre seu significado mediante a remissão repetida ao material experiencial, do qual elas 'parecem' [scheinen] derivadas, mas que, 'na realidade, já estava subordinado a elas"” (FREUD, 1967b, p. 210, grifo nosso, tradução nossa). Eis que, ao contrário do que se costuma divulgar, Freud é um pensador com um posicionamento epistemológico que nada tem a ver com um indutivismo ingênuo, que acredita na possibilidade de se efetuar observações isentas de qualquer hipótese, ao contrário, para ele, a teoria (idéias iniciais, hipóteses, premissas) precede e condiciona a observação. ${ }^{4}$

Freud toma, ainda, o cuidado de ressaltar que, embora essas idéias tenham o caráter de convenções, isso não quer dizer que são escolhidas ao acaso. Elas "são determinadas pelas relações significativas [que apresentam] com o material empírico" (FREUD, 1967b, p. 210, tradução nossa). Obviamente, a vinculação efetiva entre essas idéias iniciais e o material empírico só pode ser afirmada depois, já que no começo o investigador só pode contar com uma crença razoavel- 
mente fundamentada na pertinência dessa relação. Por isso, uma formulação mais precisa depende de um estudo paulatinamente mais aprofundado dos fenômenos; só depois disso é que os conceitos básicos de uma ciência podem ser formulados com mais precisão, passando assim a ser amplamente utilizados; só nesse estágio é que os conceitos fundamentais de uma ciência podem ser circunscritos em definições. Mas, ressalva Freud, o progresso constante da ciência não admite definições rígidas, como mostra o exemplo da física; nela, conceitos básicos bem definidos sofrem uma constante modificação em seu conteúdo.

\subsection{Pressupostos para a ConstruÇão do CONCEito de pulsão i: O CONCEITO FISIOLÓGICO DE ESTÍMULO}

Só depois de tecer considerações gerais sobre o processo de formação de um conceito teórico é que Freud faz referência ao conceito de pulsão. Escreve ele: "Um conceito fundamental [Grundbegriff] convencional desse tipo, por enquanto ainda bastante obscuro, mas do qual nós não podemos carecer na psicologia, é o de pulsão. Tentemos, a partir de diferentes ângulos, preenchê-lo com conteúdo" (FREUD, 1967b, p. 211, grifo do autor, tradução nossa). Pelo que podemos ler, pulsão seria um conceito considerado indispensável para a psicologia, um conceito fundamental da metapsicologia. Devemos entendê-lo também, pelas palavras de Freud, como um conceito ainda carente de significado, vazio de conteúdo. Conteúdo este que Freud fará provir de diversos pontos de vista, tais como o da fisiologia e da biologia. Em outras palavras, Freud define e caracteriza o conceito de pulsão a partir da comparação com conceitos e apropriação de pressupostos oriundos de outras áreas do conhecimento, no caso, da fisiologia e da biologia.

O primeiro dos conteúdos ou características da pulsão, Freud busca na comparação com o conceito fisiológico de estímulo (Reiz) e o esquema do arco reflexo. De acordo com esse esquema, quando um estímulo proveniente do mundo externo alcança a substância nervosa de um organismo, este tende a descarregá-lo para fora por meio de uma ação que o permita, p. ex., colocá-lo longe do raio de ação do estímulo. Freud considera que a pulsão poderia ser subsumida ao conceito de estímulo (Reiz), de modo que pulsão poderia ser entendida como uma variante sua, uma espécie de estímulo para o psíquico. Não devemos, porém, entender estímulo para o psíquico como equivalente da pulsão (GARCIA-ROZA, 2004).

De fato, além dos estímulos realmente pulsionais, há estímulos que podem atuar sobre o psíquico, mas que não devem ser chamados pulsionais, pois são mais parecidos com os estímulos fisiológicos. Freud dá o exemplo de uma luz forte atuando sobre o olho. Um estímulo pulsional corresponderia, p. ex., com a sede - percepção da secura da mucosa da faringe - ou a fome - irritação da membrana mucosa do estômago. Logo, uma diferença básica entre um estímulo pulsional (Triebreiz) e outros estímulos (fisiológicos) ((physiologischem) Reiz) que atuam sobre o psíquico está no fato de que um estímulo (fisiológico) provém de fora e age num único impacto, podendo, por sua vez, ser neutralizado por uma única ação apropriada, como a fuga diante de uma fonte de estímulos (BIRMAN, 2009). Já o estímulo pulsional não provém do exterior, mas do interior do organis- 
mo, razão pela qual "nunca age como uma força de impacto momentânea [momentane Stosskraft], mas sempre como uma força constante [konstante Kraft]" (FREUD, 1967b, p. 212, grifo do autor, tradução nossa). Pela mesma razão, a fuga não é de serventia diante de um estímulo pulsional, fazendo-se necessárias ações específicas para sua eliminação, ações coordenadas que promovam uma alteração adequada na fonte interna de estímulos. Freud denomina "satisfação" (Befriedigung) a suspensão do estado de carência (Bedurfnis) imposto pelo estímulo pulsional. É a partir dessas características específicas do estímulo pulsional que Freud apresenta uma descrição inicial da essência da pulsão: a) provém de fontes de estímulo localizadas no interior do organismo; e b) manifesta-se como força constante. Destas, deduz mais uma entre outras de suas características: c) a fuga é incapaz de eliminá-la, ela é irremovível. Vemos, assim, que uma primeira caracterização da pulsão é feita a partir do recurso ao conceito fisiológico de estímulo e o modelo biológico do arco reflexo.

\subsection{Pressupostos para a construção do conceito de pulsão iI:}

\section{A TENDÊNCIA BIOLÓGICA DO SISTEMA NERVOSO}

Outro elo importante para compreendermos o modo como Freud constrói o conceito de pulsão encontra-se na passagem do texto em que admite explicitamente ter aplicado sobre os dados empíricos observados na clínica, além de certas idéias iniciais, também certos pressupostos ou premissas. Escreve ele: "Nós aplicamos ao nosso material experiencial não apenas certas convenções como conceitos fundamentais, mas servimo-nos também de alguns pressupostos complicados [komplizierter Voraussetzungen]" (FREUD, 1967b, p. 213, grifo do autor, tradução nossa). E a seguir enfatiza a importância e indispensabilidade desses pressupostos no processo de elaboração conceitual dos fenômenos psicológicos, na medida em que tais pressupostos são necessários "para guiar-nos na elaboração [Berarbeitung] do mundo dos fenômenos psicológicos" (FREUD, 1967b, p. 213 , tradução nossa). Eis, portanto, mais uma constatação de que, para Freud, é a teoria, entendida como o conjunto das intuições iniciais, hipóteses e pressupostos teóricos, que condiciona a observação, quer dizer, é a metapsicologia que nos serve de caminho ou método na orientação pelos processos psíquicos inconscientes que supomos na base dos fenômenos presentes na clínica ou na cultura.

Um desses pressupostos aos quais Freud se refere já teria sido mencionado na discussão o conceito fisiológico de estímulo, embora não de forma explícita. Trata-se do pressuposto biológico que tem a ver com a tendência ou finalidade [Zweckmässigkeit], segundo a qual, "o sistema nervoso é um aparelho ao qual foi conferida a função de livrar-se dos estímulos que lhe chegam, de reduzi-los a um nível tão baixo quanto possível, ou, se fosse possível, de conservar-se absolutamente livre de estímulos" (FREUD, 1967b, p. 213, tradução nossa). Vale observar que Freud fazia uso desse pressuposto biológico há mais de duas décadas, aparecendo explicitamente em "Projeto de uma Psicologia", de 1895 (FREUD, 1987). Trata-se do princípio de inércia e seu sucedâneo, o princípio da constân- 
cia, posteriormente, no capítulo VII de "A Interpretação dos Sonhos", de 1900 (FREUD, 1961a), denominado princípio do desprazer, para, finalmente, a partir do texto, "Formulações sobre os dois princípios do funcionamento psíquico", de 1911 (FREUD, 1964b), receber o título definitivo de princípio do prazer.

Assim, se a função do sistema nervoso é a de lidar com os estímulos, percebe-se que o conceito de pulsão complica o esquema fisiológico do arco reflexo, pois, os estímulos pulsionais, por serem de origem interna, não podem ser eliminados por este mecanismo reflexo, exigindo do sistema ações muito mais complexas e numerosas. "Elas apresentam assim exigências mais altas ao sistema nervoso, levando-o a desenvolver atividades complicadas, encadeadas entre si, que modificam de tal modo o mundo externo, que ele serve à satisfação das fontes internas de estímulos" (FREUD, 1967b, p. 213, tradução nossa). Mas, sobretudo, continua Freud, os estímulos pulsionais obrigam o sistema nervoso a renunciar ao propósito ideal [ideale Absicht], mencionado antes, de manter afastados os estímulos, porque, como sabemos (GARCIA-ROZA, 2004; BIRMAN, 2009), esse tipo de estímulo atua como uma força constante, afluindo de modo contínuo e inevitável. Por isso, conclui Freud (1967b, p. 213-214, tradução nossa), "as pulsões, e não os estímulos externos, são os verdadeiros motores do progresso, que levaram o sistema nervoso, de infinita capacidade de rendimento, ao seu nível de desenvolvimento atual".

\subsection{FunÇÃo EPISTEMOLÓGICA do CONCEITO dE PULSÃo NA METAPSICOLOGIA: A NATUREZA ERÓGENA DA REALIDADE PSÍQUICA}

O primeiro significado do conceito de pulsão, compreendido como conceito-limite, parece representar uma estratégia heurística introduzida por Freud para superar justamente as dificuldades contidas numa concepção paralelista entre o físico e o psíquico, senão vejamos. Em 1891, no texto intitulado Sobre a concepção das afasias, escreve ele:

A cadeia dos processos fisiológicos no sistema nervoso provavelmente não se apresenta em relação de causalidade com os processos psíquicos. Os processos fisiológicos não cessam tão logo tenham começado os psíquicos, pelo contrário, a cadeia fisiológica prossegue, só que, a partir de um certo momento, cada elo seu (ou elos isolados) corresponde um fenômeno psíquico. O psíquico é assim um processo paralelo ao fisiológico ("um concomitante dependente") (FREUD, 1891, p. 56-57, tradução nossa). ${ }^{5}$

Quer dizer, embora seja difícil e talvez mesmo pouco provável um conhecimento definitivo sobre o modo de relação entre esses dois aspectos da vida, certas intuições teóricas (conceitos iniciais), conjugadas com outras premissas biológicas (princípio do prazer, p. ex.) e aplicadas ao material de longa data observado na clínica possibilitaram-lhe forjar um conceito mediante o qual pôde conceber os limites do terreno passível de uma investigação psicológica, mas, sobretudo, 
afirmar a natureza erógena da realidade psíquica assim concebida. Basta-nos recordar do texto de 1893 sobre as paralisias histéricas (FREUD, 1964a) que cedo sinalizaram a Freud a necessidade de conceber algum tipo de interação entre as dimensões psíquica e física. Nesse sentido, a doutrina da pulsão poderia ser tomada como uma tentativa de Freud de tematizar um problema perene não só na filosofia, mas crucial para nós psicólogos, o problema da relação entre o mental e o corporal. ${ }^{6}$

Mas, é o segundo significado do conceito de pulsão, como "representante psíquico", que nos ajuda a compreender melhor o que consideramos uma tentativa de superação da doutrina paralelista de afasias. Lá havia na discussão freudiana um componente nominalista, no sentido de que certos "nomes", como "associação" e "sensação", p. ex., teriam uma existência puramente lingüística, no sentido de que seriam dois nomes com os quais designaríamos apenas aspectos diferentes de um mesmo processo. Tais nomes teriam funções puramente analíticas, pois seriam resultados de abstrações, em dois sentidos, de um mesmo processo fisiológico, senão vejamos: "É possível, agora, distinguir no correlato fisiológico da sensação a parte da 'sensação' daquela da 'associação'? Claro que não. 'Sensação' e 'associação' são dois nomes com os quais nós recobrimos diferentes perspectivas do mesmo processo" (FREUD, 1891, p. 58, tradução nossa). Embora possa encontrar-se no texto de 1915 uma concepção convencional acerca dos conceitos, há uma diferença. Agora, o conceito de pulsão implica outras noções, e encontra-se numa relação funcional com outros conceitos e noções, como a de inconsciente, representação, repressão etc., participando da constituição de uma rede conceitual com uma função epistemológica explícita. Isto é, em 1915, Freud continua sendo o mesmo médico e cientista de 1891, mas não só. Em 1915 já se tornara o médico e cientista de uma ciência nova, o psicanalista fundador do que se apresenta como uma nova disciplina do conhecimento (FREUD, 1967e). Na ciência nova em que, como vimos, os conceitos, teorias e método encontram-se indissociavelmente enlaçados com os fenômenos descobertos/construídos, o antigo nominalismo de afasias parece não ter mais lugar. Seja qual for a compreensão que se tenha acerca do estatuto de uma teoria, nesse momento das elaborações de Freud, epistemologicamente falando, a natureza da psicanálise que tem em mente não difere da natureza de outros campos do conhecimento, nos quais conceitos e teorias desempenham papel chave. Não é à toa que nas linhas iniciais do texto de 1915 faz referência a física, como assinalamos. Conviria lembrar que é também a propósito do papel determinante das pulsões na explicação das neuroses e na demarcação e autonomia da psicanálise em relação às disciplinas adjacentes, que em 1917 Freud a compara com a química. Diz ele: "Nossa parcialidade é como a do químico, que reduz [zurückführt] todas as constituições à força da atração química. Não é por causa disso que ele nega a força da gravidade, ele deixa sua apreciação para o físico" (FREUD, 1966a, p. 5, tradução nossa).

O conceito de pulsão permite-nos, portanto, compreender os fenômenos psíquicos pulsionais como aqueles que representam, no sentido de estar no lugar de outra coisa. Isto é, a pulsão seria a representante dos estímulos corporais no psiquismo. Mas aqui Freud se depara com uma dificuldade inexistente em afa- 
sias. Lá, a necessidade era encontrar uma maneira de separar metodologicamente ao máximo a dimensão psicológica da dimensão fisiológica dos processos da linguagem: "Nós examinaremos, agora, quais são as hipóteses necessárias para a explicação das perturbações da linguagem [...] Para tanto, nós separaremos o máximo possível um do outro o lado psicológico e o anatômico do tema" (FREUD, 1891, p. 75, tradução nossa). Agora, trata-se de compreender o modo de relação entre essas duas dimensões. Como essa relação poderia ser concebida à luz do conceito de pulsão? Sabemos que desde o texto sobre as paralisias histéricas, de 1893, Freud (1964a) já havia demonstrado os limites da concepção fisicalista dominante, que defendia o determinismo do físico sobre o psíquico, determinismo este que reduzia o alcance da terapia, uma vez que a causa última das perturbações mentais continuava a ser atribuída à degeneração hereditária (FREUD, 1964c).

Assim, nos primórdios da psicanálise, o interesse teórico era impulsionado pela necessidade prática, que requeria formas eficientes de intervenção terapêutica. Entre outras dificuldades teóricas, tratava-se de tentar superar a confusão presente na concepção fisicalista corrente, que tomava eventos psicológicos como epifenômenos dos processos fisiológicos. Como vimos, a estratégia de Freud (1891) foi adotar em Sobre a concepção das afasias a doutrina da concomitância, defendida por Hughlings Jackson, segundo a qual, "[..] precisamos estar em guarda contra a falácia de que o que são estados físicos nos centros mais baixos se transformam em estados psíquicos nos centros mais altos; que, por exemplo, vibrações dos nervos sensoriais tornam-se sensações [...]" (JACKSON apud FREUD, 1891, p. 57, tradução nossa). A doutrina da concomitância era útil para demarcar metodologicamente o terreno do psicológico, ao mesmo tempo em que possibilitava tomar o psíquico como algo autônomo, mas não independente, em relação ao fisiológico. Essa demarcação oferecia as condições necessárias e metodologicamente suficientes para que Freud pudesse apresentar sua própria concepção sobre as afasias.

Em 1915, no entanto, há um avanço nessa concepção, conforme já observamos. Tal avanço é mais claramente manifesto justamente pelo segundo significado contido no conceito de pulsão, como representante psíquico dos estímulos corporais. Duas décadas de investigação teriam possibilitado a Freud lançar alguma luz sobre o abismo persistente entre o psicológico e o fisiológico, aberto desde a adoção da doutrina jacksoniana da concomitância. Mas, também aqui, é importante determo-nos um pouco sobre o sentido das palavras utilizadas por Freud. Antes, com a concomitância, tratava-se da estratégia metodológica voltada para a distinção entre o aspecto da linguagem a ser abordado pelo psicólogo daquele abordado pelo fisiologista do sistema nervoso. Agora, a relação em jogo é entre o psíquico e o corporal, conforme implicada no significado do conceito de pulsão que interessa-nos enfatizar: "representante psíquico dos estímulos que provêm do 'interior do corpo' [Körperinnern] e alcançam a alma [e] medida da exigência de trabalho imposto ao anímico em conseqüência de sua relação com o 'corporal' [Körperlichen]” (FREUD, 1967b, p. 214, grifo nosso, tradução nossa). Um detalhe que pode ser considerado aparentemente indiferente ou mesmo irrelevante, mas que parece ter suas implicações. 
Porque, se pelo conceito de pulsão Freud tenta dar conta da maneira como os estímulos corporais são presentificados no psiquismo, pode-se perguntar de que corpo se trata em psicanálise? ${ }^{7}$ Não se trata mais, certamente, do corpo fisiológico, deixado aos cuidados do fisiologista, em favor do psicológico, próprio ao estudo da linguagem, tematizado desde o estudo sobre as afasias, de 1891; nem deve se tratar do corpo investigado pela anatomia, cujas teorias foram demonstradas serem insuficientes para explicar as paralisias histéricas, desde 1893 (FREUD, 1964a). Duas indicações sobre a natureza do corpo implicadas no conceito de pulsão podem ser explicitadas ao retomarmos esse texto de 1893 e o relacionarmos ao texto de 1905, Três ensaios sobre a teoria sexual (FREUD, 1961b). Freud demonstrara que na base da paralisia histérica do braço não se encontraria qualquer determinação anatômica, mas unicamente uma alteração no delegado/ representante psíquico (psychischen Repräsentant), ocasionada pela repressão, que cindiu e fez esvaziar de afeto o componente ideativo, a idéia popular de braço. Assim, na paralisia histérica trata-se da delegação/representação de uma parte do corpo no psiquismo, mediante a idéia de braço com sua significação popular. Por conseguinte, o mesmo tipo de delegação/representação e significação não poderia ocorrer com o corpo no seu todo?

De fato, o modo em que se conforma essa delegação do corporal no e pelo psíquico pode ser esclarecida pelas descobertas de Freud sobre a sexualidade infantil. Trata-se das hipóteses sobre as zonas erógenas, áreas corporais privilegiadas como fonte das chamadas pulsões parciais, enfim, hipóteses que implicam não só na transposição pulsional de erogeneidades de início parciais e isoladas, mas, finalmente, no nascimento de um corpo pulsional, erógeno em sua totalidade. A esse propósito, pedimos licença ao leitor para citar uma longa passagem do texto sobre o narcisismo, de 1914, em que Freud trata da hipocondria, mediante as quais define o termo erogeneidade e esclarece o modo que esta é transposta ao psíquico:

Nós chamamos a atividade pela qual uma área do corpo envia estímulos sexualmente excitantes para a vida psíquica sua erogeneidade, e consideramos que nós, mediante as elucidações da teoria sexual, estamos há muito familiarizados com a concepção de que certas outras áreas do corpo - as zonas erógenas - poderiam substituir os órgãos genitais e comportar-se de maneira análoga a eles, então, temos que arriscar apenas um passo adiante. Podemos decidir considerar a erogenidade como propriedade geral de todos os órgãos, e poderíamos assim falar do aumento ou diminuição da mesma em uma determinada área do corpo. A cada uma dessas alterações da erogeneidade no interior dos órgãos poderia ser-lhe paralela [parallel] uma alteração da ocupação libidinal [Libido-besetzt] dentro do eu (FREUD, 1967a, p. 150, grifo do autor ).

A transposição para o psíquico das excitações sexuais nascidas no corpo, mediatizada pela pulsão, implicaria, portanto, na emergência e constituição de um psiquismo indissociável da evolução da erogeneidade corporal. Nesse sentido, a 
perspectiva pulsional aparece como uma perspectiva privilegiada, a partir da qual podemos começar a compreender a afirmação freudiana posta em 1923, segundo a qual "o eu é sobretudo uma essência-corpo; é não só um essência-superfície, senão ele mesmo a projeção de uma superfície" (FREUD, 1967f, p. 253, tradução nossa); e, também, a hipótese de trabalho, relativa à espacialidade constitutiva de nossas percepções como resultante da projeção do aparelho psíquico, registrada em notas ao final da vida, na qual conclui: "a psique é extensa e nada sabe disso" (FREUD, 1966b, p. 152, tradução nossa). Desse ponto de vista, por serem mediatizados por transposições pulsionais, os processos subjetivos não devem ser concebidos como separados dos processos corporais. Em outras palavras, os processos subjetivos não devem mais ser concebidos como psíquicos em sentido vago nem como processos de natureza impessoal e a-histórica, desprovidos de sentido e valor, ao contrário, devem ser concebidos como fundados na transposição da erogeneidade própria de um corpo cujas significações são constituídas ao longo de uma história singular, protagonizada pelo interjogo de séries biológicas e culturais. A implicação dessa leitura, se ela for correta, é que, no limite, a significação dos processos subjetivos encontrar-se-ia no corpo próprio.

\section{Considerações finais}

Em termos epistemológicos, a pulsão pode ser considerada o conceito fundador, organizador, cujo caráter eminentemente teórico, portanto, geral e abstrato, estende-se ao todo da metapsicologia. Pela mesma razão, trata-se do conceito basilar mediante o qual Freud pôde demarcar o alcance e limite da psicanálise, afinal, analogamente ao químico que mantém-se dentro do domínio de estudo das forças químicas, também o psicanalista tem nas forças psíquicas pulsionais o limite ultimo a circunscrever o campo passível de investigação pelo método psicanalítico. Quer dizer, a compreensão do estatuto do conceito de pulsão como um conceito fundador serviria para consolidar nossa visão sobre a natureza conceitual da metapsicologia, cuja elaboração encontra-se presente desde os primeiros trabalhos de Freud (CAROPRESO, 2008).

Como um bom cientista médico formado no clima cientificista da segunda metade do século dezenove, Freud não se contentava com a obtenção apenas de leis empíricas, obtidas paulatinamente mediante a observação cotidiana na clínica e cuja utilidade estaria limitada apenas ao universo experiencial do qual foram extraídas, etapa esta que favoreceria a opinião sobre os ofícios terapêuticos como "arte". Seu objetivo era mais amplo, buscava as então chamadas leis científicas, isto é, buscava as generalizações teóricas mais abrangentes possíveis, as únicas consideradas, segundo certos autores que leu e citou, como Stuart Mill e Hughlings Jackson (FREUD, 1891), verdadeiramente científicas, únicas capazes de contribuir para o aprofundamento do conhecimento. Em outras palavras, pelo que discutimos até aqui, para Freud, o saber psicanalítico não poderia ser entendido senão em seus dois sentidos indissociáveis, conhecimento científico e terapêutica das mazelas da alma (FREUD, 1967e). Daí também o sentido no qual entendemos a metapsicologia freudiana e a seriedade de seu projeto metapsicológico. Metapsicologia, como meta-psicologia, além-da-psicologia, designa, em nosso 
entender, acima de tudo, um terreno alternativo à vaga e imprecisa subjetividade tematizada pelas psicologias e outras disciplinas das humanidades. O campo da psicanálise seria aquele da erogeneidade própria da realidade psíquica.

Por sua natureza transitiva, o processo designado pelo conceito de pulsão é inapreensível em si mesmo, mas apreensível apenas por seus efeitos sobre o psiquismo. Foi justamente a partir da análise desses efeitos em suas diferentes manifestações, como nos sonhos, nos sintomas, nos atos falhos etc., que Freud pôde, por inferência, chegar lentamente à elaboração conceitual da pulsão e demais conceitos que perfazem a rede teórica da metapsicologia. Assim, mediante a consideração do conceito de freudiano de pulsão, todos os fenômenos humanos são pulsionalmente constituídos, quer dizer, em todos os eventos psíquicos encontram-se presentificadas qualidades pulsionais, erógenas. Trata-se, portanto, de uma concepção holista que não apenas considera a indissociabilidade entre o anímico e o corporal, mas, sobretudo, outorga ao corpo seu lugar de origem na psicanálise freudiana.

É pelo caminho desse tipo de leitura que consideramos a necessidade de avançar para além dos estudos costumeiramente descritivos, com o intuito de elucidar nos processos psíquicos supostos na base dos fenômenos clínicos e culturais seus aspectos econômico, tópico e dinâmico, afinal, para Freud, a metapsicologia não deixava de designar também um método de investigação (DELRIEU, 2009). $\mathrm{Na}$ medida em que estejamos melhores fundamentados conceitualmente, talvez possamos dispor, para além dos interesses políticos e disputas institucionais, de horizontes de interlocução mais frutíferos, não apenas com a neurociência e a psicossomática contemporâneas, mas também com os discursos sociológicos hoje predominantes entre as humanidades.

\section{Notas}

${ }^{1}$ Para um exame abrangente do artigo de Freud sobre a pulsão, Garcia-Roza (2004) e Birman (2009); e para uma discussão tematicamente mais variada sobre a pulsão, Nagera (1993), Moura (1995) e Violante (2004).

${ }^{2}$ Convém esclarecer que a pulsão já aparece na obra de Freud (1961b, 1987) desde 1905, em Três ensaios de teoria sexual, e mesmo antes, em descrições ainda não especificamente conceituais, como em 1895, em Projeto de uma psicologia (p. ex., NAGERA(1993), GARCIA-ROZA (2004)). Porém, dado nosso objetivo neste artigo, partimos da definição estrita apresentada por Freud em 1915.

${ }^{3}$ Cumpre esclarecer que ao longo de um movimento do pensamento (MONZANI, 1989), ou seja, com o paulatino aprofundamento teórico e clínico acerca dos processos psíquicos inconscientes, em 1915, Freud (1961a) pôde compreender que a repressão não separa o afeto integral, toda a libido associada a uma representação desejada, mas apenas impede a animação de seus componentes lingüísticos, as representações-palavra, impedindo assim o acesso da libido à motilidade, verbal ou comportamental.

${ }^{4}$ Ao insistir sobre esse aspecto da epistemologia freudiana não estamos afirmando que o fazer psicanalítico consiste na mera aplicação da metapsicologia aos fatos clínicos. Não cremos na valorização da teoria até o limite de um dogmatismo, como tampouco cremos na supervalorização da prática até o limite de um ecletismo. Nossa compreensão é a de que, embora em Freud a experiência psicanalítica em todos os seus níveis esteja implicada com a interdependência entre prática, técnica e teoria, a apreensão da realidade do psiquismo, conforme concebida por Freud, bem como uma intervenção psicanaliticamente orientada, encontram na metapsicologia e no modo metapsicológico de pensar (DELRIEU, 2009) a condição sine qua non. 
${ }^{5}$ Uma discussão sobre a concepção de concomitância dependente em Freud pode ser encontrada em Winograd (2004).

${ }^{6}$ Para a discussão mais ampla sobre a relação entre o psíquico e o corporal em Freud, ver Borges (2011).

${ }^{7}$ Além do mencionado texto de Borges (2011), que discute o entrelaçamento entre o psíquico e o corporal em Freud numa perspectiva epistemológica como a que tentamos indicar neste artigo, abordagens próximas podem ser lidas em Bastos (1998) e Violante (2004). Para uma visão psicossomática, ver Ávila (2002, 2004); e para abordagens predominantemente lacanianas sobre o corpo, ver Elia (1995) e Alberti e Ribeiro (2004).

\section{REFERÊNCIAS}

ALBERTI, S.; RIBEIRO, M. A. C. (Org.). Retorno do exílio: o corpo entre a psicanálise e a ciência. Rio de Janeiro: Contracapa, 2004.

ÁVILA, L. A. O eu e o corpo. São Paulo: Escuta, 2004.

ÁVILA, L. A. Doenças do corpo e doenças da alma. 3. ed. São Paulo: Escuta, 2002.

BASTOS, L. A. M. Eu-corpando: o ego e o corpo em Freud. São Paulo: Escuta, 1998.

BIRMAN, J. As pulsões e seus destinos: do corporal ao psíquico. Rio de Janeiro: Civilização Brasileira, 2009.

BORGES, G. F. O entrelaçamento do psíquico com o corporal em Freud: sobre o estatuto do campo da psicanálise. 2011. Dissertação (Mestrado)-Universidade Estadual de Maringá, Maringá, 2011.

CAROPRESO, F. O nascimento da metapsicologia. São Carlos: EDUFSCar, 2008.

CHALMERS, A. F. O que é ciência afinal? São Paulo: Brasiliense, 1993.

DELRIEU, A. La métapsychologie de Freud: exposé critique. Paris: Economica/ Anthropos, 2009.

DUDEN. Das grosse Wörterbuch der deutschen Sprache. Mannheim: Dudenverlag, 1999. 10 bändes.

ELIA, L. Corpo e sexualidade em Freud e Lacan. Rio de Janeiro: Uapê, 1995.

FREUD, S. Zur Auffassung der Aphasien. Viena: Franz Deuticke, 1891.

FREUD, S. Das Unbewusste. In: . Sigmund Freud Gesammelte Werke.

Frankfurt: S Fischer, 1961a. Bd. 10, S. 263-303. 
FREUD, S. Drei Abhandlungen zur Sexualtheorie. In:

Gesammelte Werke. Frankfurt: S Fischer, 1961b. Bd. 5., S. 27-145.

. Sigmund Freud

FREUD, S. Quelques considérations pour une étude comparative des paralysies motrices organiques et hystériques. In:

Werke. Frankfurt: S. Fischer, 1964a. Bd. 1., S. 38-55.

FREUD, S. Formulierungen über die zwei Prinzipien des psychischen Geschehens. In: _. Sigmund Freud Gesammelte Werke. Frankfurt: S. Fischer, 1964b. Bd. 8., S. 230-238.

FREUD, S. L'hérédité et l'étiologie des névroses. In: Sigmund Freud Gesammelte Werke. Frankfurt: S. Fischer, 1964c. Bd. 1., S. 407-422.

FREUD, S. Eine Schwierigkeit der Psychoanalyse. In: . Sigmund Freud Gesammelte Werke. Frankfurt: S. Fischer, 1966a. Bd. 12., S. 03-12.

FREUD, S. Ergebnisse, Ideen, Probleme. In: Werke. Frankfurt: S. Fischer, 1966b. Bd. 17., p. 151-152. . Sigmund Freud Gesammelte

FREUD, S. Zur Einführung des Narzissmus. In: Gesammelte Werke. Frankfurt: S Fischer, 1967a. Bd. 10., S. 137-170.

Sigmund Freud

FREUD, S. Triebe und Triebschicksale. In: . Sigmund Freud Gesammelte Werke. Frankfurt: S. Fischer, 1967b. Bd. 10, S. 210-232.

FREUD, S. Die Verdrängung. In: Frankfurt: S. Fischer, 1967c. Bd. 10. S. 248-261.

FREUD, S. 'Psychoanalyse' und 'Libidotheorie'. In: Sigmund Freud Gesammelte Werke. Frankfurt: S Fischer, 1967e. Bd. 13., S. 211-233.

FREUD, S. Das Ich und das Es. In: Frankfurt: S Fischer, 1967f. Bd. 13., S. 237-289.

FREUD, S. Entwurf einer Psychologie. In: Sigmund Freud Gesammelte Werke. Frankfurt: S. Fischer, 1987. Nachtragsband, S. 375-477.

GARCIA-ROZA, L. A. Introdução à metapsicologia freudiana 3: artigos de metapsicologia. Narcisismo, pulsão, recalque, inconsciente (1914-1917). 6. ed. Rio de Janeiro: J. Zahar, 2004.

HANNS, L. A. Comentários do editor brasileiro. In: FREUD, S. Escritos sobre a psicologia do inconsciente. Rio de Janeiro: Imago, 2004. v. 1., p. 137-144. 
LAPLANCHE, J.; PONTALIS, J. B. Vocabulario de psicanálise. 4. ed. São Paulo: Martins Fontes, 2001.

MONZANI, L. R. Freud: o movimento de um pensamento. Campinas: EDUNICAMP, 1989.

MOURA, A. H. (Org.). As pulsões. São Paulo: Escuta/Educ, 1995.

NAGERA, H. (Org.). Conceitos psicanalíticos básicos da teoria dos instintos. 10. ed. São Paulo: Cultrix, 1993.

SOUZA, P. C. As palavras de Freud: o vocabulário freudiano e suas versões. São Paulo: Companhia das Letras, 2010.

VIOLANTE, M. L. V. Ensaios freudianos em torno da psicossexualidade. São Paulo: Via Lettera, 2004.

WINOGRAD, M. Entre o corpo e psiquismo: a noção de concomitância dependente em Freud. Psychê, São Paulo, v. 8, n. 14, p. 95-108, jul/dez. 2004.

Recebido em: 13 de outubro de 2010 Aceito em: 28 de março de 2011 